Article

\title{
Do Consumers of Environmentally Friendly Farming Products in Downstream Areas Have a WTP for Water Quality Protection in Upstream Areas?
}

\author{
Saem Lee ${ }^{1, *}$, Trung Thanh Nguyen ${ }^{2}$, Hyun No Kim ${ }^{3}$, Thomas Koellner ${ }^{1}$ and Hio-Jung Shin ${ }^{4}$ \\ 1 Professorship of Ecological Services (PES), BayCEER, University of Bayreuth, 95440 Bayreuth, Germany; \\ thomas.koellner@uni-bayreuth.de \\ 2 Institute for Environmental Economics and World Trade, University of Hannover, 30167 Hannover, \\ Germany; thanh.nguyen@iuw.uni-hannover.de \\ 3 Environmental Policy Research Group, Korea Environment Institute, Sejong 30147, Korea; hnkim@kei.re.kr \\ 4 Department of Agricultural and Resource Economics, Kangwon National University, Chuncheon 24341, \\ Korea; hiojung@kangwon.ac.kr \\ * Correspondence: Saem.Lee@uni-bayreuth.de; Tel.: +49-921-55-2574
}

Received: 23 February 2017; Accepted: 4 July 2017; Published: 12 July 2017

\begin{abstract}
In South Korea, the Soyang Lake is an important source of drinking water to the metropolitan areas including Seoul. However, water quality problems in the Soyang Lake have still remained due to chemical contaminations attributed to conventional farming practices in the upstream areas. Based on a downstream consumer survey using a contingent valuation method, this study estimated the expected willingness to pays (WTPs) for water quality improvement through the conversion to environmentally friendly farming (EFF). The results showed that the estimated annual mean WTP is KRW 36,115 per household. The aggregated WTPs of downstream respondents in the Soyang Lake are sufficient to compensate for the income losses of upstream EFF farmers in highland farming areas. In addition, we found that the downstream citizens who recognize the label for EFF products and who intend to purchase EFF products in the future have a significant impact on WTPs for water quality improvement.
\end{abstract}

Keywords: water quality improvement; willingness to pay; compensation scheme; conversion to environmentally friendly farming

\section{Introduction}

The Soyang Lake is the largest artificial lake created by the construction of the Soyang Dam and is located at the upper reaches of the North-Han River in South Korea. This lake is an important source of drinking water to downstream metropolitan areas [1]. The maintenance of clean water quality in the upstream areas of this lake has been one of the most critical issues for several years to ensure healthy aquatic ecosystem services which provide many benefits to the society. However, conventional farming practices which overuse chemical fertilizers and pesticides have dominated especially in the highland areas of the upstream regions, which have caused soil erosion into the water and consequently resulted in deterioration of water quality. The decrease in water quality levels is problematic not only for drinking water but also for the aquatic ecosystem health and the management [2].

In an attempt to improve water quality, the government has proposed the conversion from conventional farming to environmentally friendly farming (EFF) in the upland areas as one of the alternative measures for the water quality improvement. However, despite the continued efforts to promote EFF, the proportion of conversion to EFF by upstream farmers has been low [1]. The main reason is that conversion to EFF would lead to loss of income for upstream farmers. Obviously, both 
ecosystem service providers in upstream areas and its users in downstream areas play an important role for sustainable water resources management. In this context, it is important to make systematic efforts helpful to find practical solutions that can satisfy both stakeholders.

A contingent valuation method (CVM) is utilized to measure the non-market values of change in environmental and natural resources in a stated preference approach [3]. Compared to the revealed preference approach, such as travel cost methods and hedonic price methods, which are based on actual behaviors revealed by decision-makers to estimate the value of goods and services, the CVM is more flexible and useful to estimate non-use values associated with change in conditions of environmental resources based on hypothetical scenarios [4]. With respect to water-related services, a number of existing literatures using CVM have provided empirical estimates of willingness to pay (WTP) for water quality improvement [5] combined with an agricultural policy [6,7], irrigation water use [8] and waste management improvement [9].

In connection with organic agricultural practices, previous studies estimated and analyzed the WTP for price premium of organic agricultural products due to environmental and health concerns $[10,11]$. Some studies identified the determinants of organic food purchase such as knowledge, attitudes and price consciousness towards organic products $[12,13]$. In addition, many studies showed the conversion to organic farming can have a potential to improve the water quality dominated by agricultural land use [14-16]. Other studies have emphasized that sustainable agricultural management practices such as organic farming and EFF can have positive effects on water quality improvement by reducing agricultural nonpoint source pollution $[17,18]$. In South Korea, several studies focused on an estimation of the WTP for improving water quality using CVM [19,20]. However, with respect to water quality conservation combined with a change in farming practices, less attention has been paid to assess the expected WTP for water quality improvement through the conversion to EFF.

Furthermore, payments for environmental services (PES) have been given much attention as a policy instrument to improve water-related ecosystem services in connection with farming practices. This aims to reduce/support negative/positive environmental externalities by transferring financial resources from downstream water users (beneficiaries) who benefit from clean water quality, to upstream farmers (service providers) who receive compensation by changing their farming practices [21]. Many PES schemes have been established and implemented in developed countries, such as the European Union and the United States, to motivate farmers to change their farming practices [22-25]. However, such attention on water-related ecosystem service valuation is currently much less in Asia in general and in South Korea in particular.

In terms of changes in farm management practices, many studies focused on key factors determining the adoption of conservation practices and on its accompanying challenges [26-30]. Several studies reported that decreased yields and increased farming costs during the transition periods are main barriers to the adoption [31-33]. In order to overcome the barriers, providing an incentive for the conversion would be helpful for farmers to offset their income losses and to increase the probability of the adoption. A financial incentive would encourage farmers to adopt the conservation practices.

In this context, our study aims to estimate the downstream households' WTPs (benefits) for water quality improvement by implementing EFF and to compare these benefits to the costs required for compensation for lost income of upstream farmers. Moreover, in the current literature, most studies focused on only one perspective, either benefits or costs, which might not provide sufficient information for successful policy-making [34]. Thus, our study considered both aspects with respect to water quality improvement, which is different from previous studies. In detail, this study estimates the expected WTP of downstream water users for water quality improvement through the conversion to EFF in the Soyang Lake of South Korea, and examines whether the WTP would be sufficient to cover the costs required to compensate for the loss of earnings that can occur for upstream farm households due to the shift to EFF practices. 


\section{Method}

The method of our study is organized in the following way. Based on the downstream households' survey, the annual expected WTP for water quality improvement were estimated by a bivariate probit model. Additionally, an ordinary least squares (OLS) analysis was used to identify the factors affecting the WTPs with respect to policy implication. Furthermore, based on the survey of upstream farm households in mountainous areas, we calculated the average income loss during the EFF transition periods. Finally, the aggregate WTPs for downstream households were compared with the upstream farmers' mean income loss during the transition period, in order to identify whether the benefits are sufficient to cover the required costs.

\subsection{Study Area}

The Soyang Lake is an important drinking water source to Seoul. It is the 1st tributary to the North-Han River in the Han River basin. The length of the Soyang watershed is $169.75 \mathrm{~km}$ and its catchment areas are about $1852 \mathrm{~km}^{2}$. In terms of aquatic ecosystem services, this watershed is home to threatened and endangered species and provides recreational functions along the river basin. To maintain good water quality, the government of South Korea implemented the water management policy, which has been running since the 1970s. Although clean water quality has been maintained in the river basin, potential deterioration of the water quality caused by intensive agricultural practices in the upstream areas of the river basin is still remaining, especially during the monsoon season under climate change.

One of the beneficiaries among downstream areas along the river basin that this study considers is Seoul (latitude $37^{\circ} 33^{\prime} \mathrm{N}$, longitude $126^{\circ} 58^{\prime} \mathrm{E}$ ), which is the capital and the largest city ( 25 districts, $605.25 \mathrm{~km}^{2}$ ) of South Korea, with a population of approximately 10 million people. This city is one of the representative downstream beneficiaries, being provided with clean water as well as aquatic ecosystem services from the upstream areas where economic activities are restricted to some extent to sustain water quality conditions [1].

Among upstream regions along the river basin, this study considers Gangwon Province which is located in the mountainous northeastern side of South Korea (latitude $37^{\circ} 02^{\prime} \mathrm{N}-38^{\circ} 37^{\prime} \mathrm{N}$ and longitudes $127^{\circ} 05^{\prime} \mathrm{E}-129^{\circ} 22^{\prime} \mathrm{E}$ ). This province consists of 18 counties and its total area is about $16,874 \mathrm{~km}^{2}$. Total cultivated areas of farmland in this province were 112,007 ha and more than $90 \%$ of farms in this region used conventional farming practices in 2012. The main crops cultivated in this province are Chinese cabbages and radishes, which use a large amount of chemical fertilizers and pesticides. In this province, three districts including Hongcheon, Inje, and Yanggu are the main districts where most farming is activated in the mountainous areas, which resulted in soil erosion into the river having negative impacts on water quality. These districts can be regarded as hot spots of non-point source pollution in monsoon climate (See Lee et al. [1] for more details). The conventional farming in these districts has been blamed for one of the main factors which cause degradation of water quality during the monsoon period. Such water pollution has been long debated between upstream and downstream areas with respect to water management issues (See Lee et al. [1] for more details).

\subsection{Downstream Consumers Survey: Data and Study Design}

The survey was administered from 4th to 28th of March 2013 by a professional survey company with trained interviewers. A face-to-face survey was carried out at the Nonghyup supermarket, one of the biggest supermarkets selling both conventional agricultural products and EFF products in Seoul to collect heterogeneous consumers. Prior to implementing the questionnaire to final survey samples, we held a focus group discussion to optimize responses and ensure accuracy by adjusting question wording and format of the questions. For incentives to respond to the survey, a gift was provided only to those who completed the survey. Before starting the survey, we randomly selected respondents and asked whether they are Seoul residents or not. Using this procedure, we collected 210 completed 
responses, which included 105 consumers who purchased EFF products and 105 consumers who had not. The sample size of Seoul population is in the $7 \%$ sampling error. Note that the incomplete survey cases were excluded for the analysis. The profile of survey respondents is presented in Table S1 in the Supplementary Materials. In addition, Table S9 provides standardized mean differences (SMD) of households' characteristics regarding their annual income. This shows that there are no significant differences between the survey dataset and the dataset including Seoul households in 2013, despite the fact that there is a large difference in the total number of observations and surveyed samples. Thus, it means that our survey sample is a representative sample of Seoul households in their income mean comparisons.

The survey questionnaire was divided into three sections. In the first section, respondents were asked about their environmental perception and attitude towards the water quality and their expenditure on EFF products. In the second section, respondents were first provided the information about the past decrease in water quality of the river basin with high levels of turbidity (328NTU (Number of Transfer Units)) in South Korea. Subsequently, the respondents are told that the water quality degradation means dirty water from an influx of the muddy water and that the main reason for the degradation is an overuse of the chemical fertilizers and pesticides used by conventional agricultural practices. Next, the questionnaire informed the respondents of certain details that the water quality could be improved through the conversion to EFF from muddy water to potable water. Based on the description, the WTP questions were included in the questionnaire. Finally, in the third section, socio-economic characteristics of respondents were included such as age, education, income. The WTP question presented in the second section is as following:

"Suppose that this proposal will improve the water quality through the adoption of EFF from muddy water to fresh water along the Soyang watershed, if you would make a payment of KRW $\mathrm{A}$ in a tax. The proposal would reduce runoff from heavy rains during the monsoon period in the mountainous agricultural farmland area and would ensure more sustainable clean water supply. Remember that if this would be implemented, the water quality will be improved as a result of EFF practices from muddy water (grade 2 ) to fresh water (grade 1)".

The WTP question for the water quality improvement followed a dichotomous choice framework. The bid values presented were KRW 2000, KRW 4000, KRW 6000, or KRW 8000 and these values were randomly distributed. We used a tax referendum format because this is a compulsory contribution to avoid free-riding which might happen in voluntary contributions. Before presenting bid amounts in the WTP question, we asked if respondents agree with the presented scenario regarding the role of the watershed and information on the water quality, habitats and recreation functions that have negative impacts as a result of agricultural practices in the upstream area. The 25 respondents who disagreed with the offered scenario were excluded in the analysis.

\subsection{Downstream Consumers Survey: WTP Elicitation Formats}

A CVM is the most common stated-preference technique in non-market valuation that does not depend on observed market behavior. This method is commonly used to elicit environmental values based on a hypothetical situation for policy contribution. Individuals are directly asked for their WTP based on hypothetical scenarios for a proposed policy [35-37]. In this study, the double bounded dichotomous choice (DBDC) elicitation method was used for deriving the WTP. Although the National Oceanic Atmospheric Administration (NOAA) emphasizes the single bounded referendum method for eliciting WTP in non-market goods and services [36], the single bounded model has a disadvantage, providing inefficient welfare measures due to limited information gained from individual respondents. The DBDC model is more information intensive and asymptotically more efficient than the single bounded method $[38,39]$. The DBDC model is a close-ended format consisting of a binary response of a yes or no answer to initial values $\left(B_{1}\right)$ and follow-up values $\left(B_{2}\right)$. The follow-up WTP values depend on the respondents' response to the first WTP value that was proposed; if the first value is accepted, the second value is doubled, whereas if the first value is refused, the second value is half of the value as 
much. Thus, the DBDC method can directly offer an economic measure of individual welfare relevant to a discrete change in water quality [40]. In the dichotomous choice question format, the probability that individual's WTP is equal to or larger than presented bids $(B)$ can be written as:

$$
\operatorname{Pr}(\text { yes })=\operatorname{Pr}(W T P \geq B) \equiv 1-F_{c}(B),
$$

where $F_{c}(B)$ indicates the cumulative distribution function of WTP. According to Hanemann [41], all components of the indirect utility function are not observable. The error terms are random variables in the random utility model, the probability of the "yes" answer can be written as:

$$
\begin{gathered}
\operatorname{Pr}(\text { yes })=\operatorname{Pr}\left\{C\left(\mathrm{Q}^{0}, \mathrm{Q}^{1}, \mathrm{Y}, \mathrm{P}, \mathrm{Z}, \varepsilon \geq \mathrm{B}\right)=\operatorname{Pr}\left\{\mathrm{V}\left(\mathrm{Q}^{1}, \mathrm{Y}-\mathrm{B}, \mathrm{P}, \mathrm{Z}, \varepsilon\right) \geq \mathrm{V}\left(\mathrm{Q}^{0}, \mathrm{YP}, \mathrm{Z}, \varepsilon\right)\right\}\right. \\
\equiv 1-F_{\mathrm{C}}(B),
\end{gathered}
$$

where $(\mathrm{Q})$ indicates the scalar for being valued in environmental quality, $(\mathrm{P})$ is the vector of the prices for the market goods, $(\mathrm{Z})$ is the socio-demographic information, and $(\mathrm{Y})$ is the income of interviewed respondents. Accounting for the current situation, the utility function is considered as $V\left(Q^{0}, Y, P, Z, \varepsilon\right)$. When a change in the environmental quality, such as water quality, happens to the offered alternative scenario, the utility function is changed into $\mathrm{V}\left(\mathrm{Q}^{1}, \mathrm{Y}-\mathrm{B}, \mathrm{P}, \mathrm{Z}, \varepsilon\right)$. In this regard, the compensation variation $(C)$ indicates the expected WTP for the environmental quality. It produces the maximum WTP of respondents for the change from the initial status quo $\left(\mathrm{Q}^{0}\right)$ to changed situation $\left(\mathrm{Q}^{1}\right)$. If $\mu_{W T P}$ is equal to $\operatorname{E}\left[\mathrm{WTP}\left(\mathrm{Q}^{0}, \mathrm{Q}^{1}, \mathrm{Y}, \mathrm{P}, \mathrm{Z}, \varepsilon\right)\right], \delta_{W T P}^{2}$ is equal to $\operatorname{Var}\left[\mathrm{WTP}\left(\mathrm{Q}^{0}, \mathrm{Q}^{1}, \mathrm{Y}, \mathrm{P}, \mathrm{Z}, \varepsilon\right)\right]$ and $\mathrm{F}(\bullet)$ can be the cumulative distribution function of the standardized variate $\omega=\left(W T P-\mu_{W T P}\right) / \delta_{W T P}$, the probability function can be indicated as:

$$
\operatorname{Pr}(\text { yes })=1-F\left[\frac{B-\mu_{W T P}}{\delta_{\text {WTP }}}\right] \equiv 1-F(-\alpha+\beta B),
$$

where $\alpha=\mu_{\text {WTP }} / \delta_{\text {WTP }}$ and $\beta=1 / \delta_{W T P}$. In this dichotomous choice, the model for estimating WTP is determined by cumulative distribution function of WTP $(C), F_{c}(B)$ and distribution assumption of the random component in the utility function. If $F_{c}(B)$ follows a probit standard distribution and linear model, the expected average WTP is:

$$
E \varepsilon(W T P / \alpha, \beta, Z)=\frac{\alpha Z}{\beta}
$$

where $\alpha$ denotes the vector of parameters of the coefficient on the bid level, $\beta$ indicates the estimated marginal utility of income and $\mathrm{Z}$ means the vector of characteristics of the respondents.

A respondent $(j)$ is proposed with the first and the second bid amount for the water quality improvement in our study. The response patterns to the DBDC WTP questions were as follows: No-No $(\mathrm{NN})$ responses $\left(W T P_{j}<B_{2}\right)$, No-Yes (NY) responses $\left(B_{1} \geq W T P_{j}>B_{2}\right)$, Yes-No $(\mathrm{YN})$ responses $\left(B_{1} \leq W T P_{j}<B_{2}\right)$ and Yes-Yes $(Y Y)$ responses $\left(W T P_{j} \geq B_{2}\right)$. In a bivariate probit model, the dependent variable takes the value of 1 if the respondent accepts the proposed value and of 0 otherwise, depending on the response to the double-bounded values. Haab and McConnell [40] illustrated that ' $\mathrm{YN}$ ' and ' $\mathrm{NY}$ ' answers provide a relative clear bound of WTP and obtains ' $N N^{\prime}$ and ' $Y Y^{\prime}$ estimate efficiency. This has an advantage of reducing variance of the WTP estimates, as compared to single bounded question.

\subsection{Downstream Consumer's Survey: Empirical Model}

In DBDC format, a bivariate probit model was employed in order to calculate the mean WTP for water quality improvement. The randomly assigned initial bids for the WTP ranged from KRW 2000 to KRW 8000 per month in the four sub-samples to avoid initial bid biases (Table S3). In accordance with a bivariate Probit model equation, the dependent variable takes 1 if the respondents are willing to pay for the conversion to EFF to improve water quality, and 0 otherwise. The bid variable was 
a bid amount in KRW. The variable buyer which takes the value 1 if respondent bought EFF products, 0 otherwise. The estimates for the model are obtained through maximum likelihood techniques. The average willingness to pay is calculated with the corresponding $95 \%$ confidence intervals following the 5000 boot-strapping procedures of Krinsky and Robb [42].

Furthermore, we analyzed an OLS regression in the log formation as a way to explain the points raised in this discussion. In the OLS regression model, explanatory variables such as socio-economic variables and environmental awareness were included. It is assumed that Age, Education, Income and Children could be significant factors affecting the WTP for the water quality through the adoption of EFF. Moreover, it is expected that the respondents who have knowledge about the labels of EFF products and the future willingness to purchase have a significant effect on the WTP. The OLS model can be written as follows:

$$
\ln (Y)_{i}=\alpha_{0}+\sum \beta_{i} x_{i}+\varepsilon_{i}
$$

where $Y$ is the expected WTP calculated from a bivariate probit model, $\alpha_{0}$ and $\beta_{i}$ are parameters to be estimated, $x_{i}$ means explanatory variables and $\varepsilon_{i}$ is the stochastic error term. Based on Equation (5), the marginal effect for the continuous variables can be indicated as:

$$
\frac{\partial Y}{\partial x_{i}}=\beta_{i} * \bar{Y} \text { for continuous variables, }
$$

where $\bar{Y}$ is the mean of WTP. According to Kennedy [43], the marginal effect for dummy variables can be written in the below equation:

$$
\Delta \mathrm{D}=\left\{\exp \left(\beta_{i}-0.5 * V\left(\beta_{i}\right)\right)-1\right\} * Y_{\text {mean }}
$$

where $\Delta \mathrm{D}$ means the marginal effect for dummy variables, $V\left(\beta_{i}\right)$ is an estimates of the variance. $Y_{\text {mean }}$ is the average WTP. Based on Equations (6) and (7), we calculated the marginal effects for the explanatory variables (Table S6).

\subsection{Upstream Farmers' Data Collection and Study Design}

Face-to-face interviews were conducted with upstream farm households of the watershed. The sample size is 218 farm households including 85 conventional farms, 68 EFF farms, and 65 partially converted farms who are using both conventional and EFF practices in their own choices (see Lee et al. [1] using the same data). The farmer's list was obtained from local leaders and government staff in Gangwon Province in 2012. Due to the time and budget constraints, stratified random sampling was applied, with $7 \%$ sample size based on the total number of farm households. After a pilot-test, the final survey was implemented from March to April of 2012 with trained interviewers. The questionnaire comprised of three sections. The three types of farm households had in common the first and third sections. The second section had different questions according to their farming techniques. The first section contained their benefits including revenues and subsidies and costs including land rent, labor fertilizer, pesticides and extra costs for their cultivation among the three groups [1]. The second included conventional and partially converted farmers' response for the adoption of EFF and reasons not to adopt the EFF. Regarding the two groups, we asked if they were willing to adopt the EFF for environmental protection, when their income loss is fully compensated during the transition period. The reasons not to adopt the EFF were investigated, when they did not want to change their farming techniques under the compensation. In addition, in the case of partially converted farming and EFF, we asked different questions about their yield reduction during the transition period in the second section. On the other hand, targeting partially converted and EFF farmers, we asked about how much yield reduction occurred during the transition period from the first to the fifth year. The final section was to identify the social, economic and demographic characteristics of interviewed farm households such as age, income, education level and farming experience, farm size of farmland. 


\subsection{Calculation of Income Loss of Environmentally Friendly Farmers during Transition Period}

We calculated the income loss of EFF during the transition period as a proxy for the financial incentive in upstream areas. Given the revenue of farmers is obtained by multiplying the quantity with the price of their cultivated crops, the price can be affected by various factors such as other crops' prices, seasonal variability and weather. While price variability for each crop is challenging, changes in crop productivity and quantity can be easily detected by farmers. Thus, regarding the revenues obtained from price and crop yields, price fluctuation was not considered, since the price is influenced by various factors. The price was fixed when calculating farmers' net income loss. Only output changes were considered as their income loss by their yield reduction. In the case of no output change during the transition period, the farmers' interview data was excluded.

Regarding farm households' survey data and information, the results of Lee et al. [1] were used to calculate the income loss of EFF in our study. In order to calculate the income loss during the transition period, only quantity change in EFF practices and annual net income per ha of conventional farmers were considered in the mountainous area. Current conventional farmers are potential EFF farmers in the future who are compensated in case they convert their farming method to EFF. Thus, based on the interviews of conventional farmers, their annual net income per ha was confirmed by their revenue minus total costs in farm management practices. Targeting EFF farmers who faced the problem of yield decrease, we investigated the level of their yield reduction during the transition period in a relative term (percentage). In addition, with respect to partially converted farmers who are implementing both conventional farming and EFF, we investigated both their output reduction during the transition period and whether they were willing to adopt EFF.

If the conversion to EFF in total highland areas affecting the water quality is implemented, the current conventional farm households would be compensated for their income reduction by the conversion. Thus, the average annual net income per ha of the conventional farmers was multiplied with the average crop yield reduction rate in EFF per ha (Table S7). The decreased annual income was then multiplied with the total highland areas. The total highland upland areas affecting the water quality problem were 3925 ha reported by the Ministry of the Interior of South Korea. As the total compensation required for the conversion of the total highland areas, the calculated income loss is shown in Table 5.

\section{Result}

\subsection{Downstream Citizens' WTP for Water Quality Improvement through EFF}

The descriptive statistics for downstream respondents are presented in Table S1. The distribution of the respondents' response to the corresponding first and follow-up bids is shown in Tables S2 and S3. The basic description of the variables used in a bivariate probit model is included in Table S4. These tables are in the Supplementary Materials.

Table 1 presents the estimation results of the bivariate probit model for the water quality improvement. We implemented a Wald test with the $95 \%$ confidence interval to test the relative efficiency measures between the single bounded and the double bounded models. The result shows that the double bounded model is more efficient than the single bounded model with a low ratio of confidence level. The Bid variable in logarithmic form was included in the model. With respect to the presented WTP, as expected, the coefficient of $\ln (\mathrm{Bid})$ is found to be negative and statistically significant. The variable Buyers is positively and statistically significantly correlated with the WTP decision. It means that the purchase amounts of EFF products rarely affect the WTP decision since the coefficient value of Buyers is close to zero, but are positively related with the likelihood of a yes response for the WTP.

Table 2 shows the annual mean WTPs for improving water quality by adopting EFF. The expected value of annual mean WTP is KRW 36,115 while the estimated median WTP is approximately a half of that. The lower bounded estimate is approximately KRW 27,471/year/household, assuming that respondents have a WTP of KRW 0 , if they do not want to pay for it. The upper bounded estimate is KRW 58,975/year/household on the survey. The aggregate average WTPs are about KRW 15,104,594. 
Table 1. Estimation results of a bivariate probit regression for the improved water quality.

\begin{tabular}{ccc}
\hline Explanatory Variable & Coefficient & Std. Err. \\
\hline WTP $($ Yes 1) & & \\
\hline $\ln ($ Bid 1$)$ & $-0.838217^{* * *}$ & 0.164895 \\
Buyers & $0.000004^{* * *}$ & 0.000002 \\
Constant $^{* * *}$ & 1.371691 \\
\hline WTP $($ Yes 2$)$ & $6.109605^{* *}$ & \\
\hline $\ln ($ Bid 2$)$ & & 0.111559 \\
Buyers & $-0.783377^{* * *}$ & 0.000002 \\
Constant $^{* * *}$ & $0.000004^{* * *}$ & 0.908565 \\
\hline Athrho & $5.497683^{* *}$ & 1.56 \\
rho $(\rho)$ & 3.30 & 0.01
\end{tabular}

Note: ${ }^{* * *} p<0.01 ;$ Number of observation $=1 \overline{85 ;}$ Log pseudo likelihood $=-140.46 ;$ Wald chi-square(4) $=54.42 ;$ Likelihood-ratio test of rho $=0$; chi-square $(1)=73.73$; Prob $>$ Chi-square $=0.0000$.

Table 2. An annual mean Willingness to Pays (WTPs) and aggregate Willingness to Pay (WTP) values.

\begin{tabular}{|c|c|c|c|c|c|c|c|}
\hline $\begin{array}{c}\text { Mean WTP } \\
\text { [KRW/Year] (A) }\end{array}$ & $\begin{array}{l}\text { Lower Bound } \\
\text { WTP } \\
\text { [KRW/Year] (B) }\end{array}$ & $\begin{array}{l}\text { Upper Bound } \\
\text { WTP } \\
\text { [KRW/Year] (C) }\end{array}$ & $\mathrm{CI}^{\mathrm{a}} / \mathrm{Mean}$ & $\begin{array}{l}\text { Total Number of } \\
\text { Households (D) }\end{array}$ & $\begin{array}{c}\text { Aggregate Mean } \\
\text { WTPs }^{b}(E)=(A) \times(D)\end{array}$ & $\begin{array}{l}\text { Aggregate Lower } \\
\text { Bound WTPs b } \\
{[\text { KRW 10,000/Year] }} \\
(\text { F) }=(\text { B }) \times(\text { D) }\end{array}$ & $\begin{array}{l}\text { Aggregate Upper } \\
\text { Bound WTPs b } \\
{[\text { KRW 10,000/Year] }} \\
(G)=(C) \times(D)\end{array}$ \\
\hline 36,115 & 27,471 & 58,975 & 0.87 & $4,182,351$ & $15,104,594$ & $11,488,918$ & $24,664,997$ \\
\hline
\end{tabular}

Note: The number of households is obtained from the Statistics Korea (http://stat.seoul.go.kr/jsp3/stat.book.jsp?link=6\&cot=009, accessed on 31 January 2017) in 2013. ${ }^{\text {a CI: Confidence }}$ Interval for WTP measures of Krinsky and Robb (95\%); ${ }^{\text {b }}$ Unit US\$ $1.00=$ KRW 1055.4, at the time of the survey (2013). 
3.2. Key Factors Affecting Downstream Willingness to Pay for the Water Quality Improvement through the Adoption of EFF

The OLS regression was implemented to investigate the factors affecting the WTP of downstream citizens and the results are shown in Table 3. The F-value was significant at $1 \%$ level, meaning that this OLS model was well fitted. To check for the perfect multicollinearity between the variables, the VIF test was implemented and the null hypothesis was rejected. The result of OLS model shows that the two out of six explanatory variables are found to be significant on the dependent variable $\operatorname{lnWTP}$.

Among the six variables, the Children, Age, Income and Education variable have a statistically insignificant relationship with the lnWTP. The coefficients of Future purchase intension of current consumers with EFF products and Label are statistically significant with positive signs. It demonstrates that as the current and future purchase intensions of EFF products increases, the probability of paying WTP for the water quality improvement through the adoption of EFF increases. The result also implies that consumers' awareness for labels is positively related with the lnWTP. Moreover, the higher the awareness for labels of EFF products, the higher the probability of accepting the value of the WTP.

Table 3. Coefficient estimates and standard errors of ordinary least squares (OLS) regression.

\begin{tabular}{ccc}
\hline Variable & Coefficient & Standard Error \\
\hline Future purchase intention of current consumers with EFF products & $0.0257^{* * *}$ & 0.0050 \\
Label & $0.0840^{*}$ & 0.0503 \\
Children & 0.0155 & 0.0634 \\
Age & -0.0002 & 0.0024 \\
Income & -0.0067 & 0.0177 \\
Education & 0.0021 & 0.0118 \\
Constant & $8.0861^{* * *}$ & 0.2446 \\
\hline , $^{* *} p<0.05,^{*} p<0.1$ & \multicolumn{2}{c}{185} \\
$\mathrm{~N}$ & \multicolumn{2}{c}{$5.53 * * *$} \\
F-value \\
Adjusted- $R^{2}$ & \multicolumn{2}{c}{0.13} \\
Mean VIF & \multicolumn{2}{c}{1.26} \\
\hline
\end{tabular}

\subsection{Upstream Farmers' Response and Reasons to Change Farming Technique to EFF}

Table 4 shows the response of upstream farmers for the willingness to adopt EFF when their income loss during the transition period is compensated. With respect to the yes response for the conversion to EFF, the conventional farmers account for $47.1 \%$, while partially converted farmers who are implementing both conventional farming and EFF account for $60.0 \%$. The result shows that about half of total farmers (52.7\%) are willing to convert their farming techniques to EFF, if their income loss is offset. In addition, the crucial reasons for the reluctance to adopt EFF are presented in Table S5. The main reasons not to adopt EFF in total are the farm profitability and aging problem in conventional and partially converted farmers.

Table 4. The response of upstream farmers for willingness to convert farming method to Environmentally Friendly Farming (EFF).

\begin{tabular}{cccc}
\hline Farming Techniques & $\begin{array}{c}\text { Conventional } \\
\text { Farmer }(\boldsymbol{N}=\mathbf{8 5})\end{array}$ & $\begin{array}{c}\text { Partially Converted } \\
\text { Farmer }(\boldsymbol{N}=\mathbf{6 5})\end{array}$ & Total $(\boldsymbol{N}=\mathbf{1 5 0})$ \\
\hline Yes & $40(47.1)$ & $39(60.0)$ & $79(52.7)$ \\
No & $45(52.9)$ & $26(40.0)$ & $71(47.3)$ \\
Total & $85(100)$ & $65(100)$ & $150(100)$ \\
\hline
\end{tabular}

Note: The numbers in parentheses are the proportions of surveyed farmers respectively. 


\subsection{A Comparison between Income Loss of Upstream Farmer and Aggregate WTP of Downstream Consumer}

The result of the aggregate estimated WTP of downstream respondents is shown in Table 5. Based on the total population of Seoul city obtained from the Statistics Korea in 2013, the estimated result was calculated with the above annual mean WTP of the respondents. The compensation for each farm was obtained from multiplying the calculated mean income loss during the transition period with total highland area of farm. The calculated compensation costs (KRW 60 billion) turns out to be about 40\% less than the downstream consumers' annual WTP (KRW 151 billion). This shows that the aggregate WTPs estimated from consumers' interview might be sufficient to compensate the income loss of farmers during the transition period.

Table 5. The calculated compensation costs based on highland farm size, compared with annual WTP.

\begin{tabular}{cccc}
\hline $\begin{array}{c}\text { (A) Total Highland } \\
\text { Farm Area (ha) }\end{array}$ & $\begin{array}{c}\text { (B) Annual Income } \\
\text { Loss of EFF per ha } \\
\text { [KRW 10,000/ha] }\end{array}$ & $\begin{array}{c}(\mathbf{C}=\mathbf{A} * \mathbf{B}) \text { Total } \\
\text { Annual Compensation } \\
{[\text { KRW 10,000] }}\end{array}$ & $\begin{array}{c}\text { Annual Aggregate } \\
\text { WTP [KRW 10,000] }\end{array}$ \\
\hline 3925 & 1534 & $6,020,950$ & $15,104,594$ \\
\hline
\end{tabular}

\section{Discussion}

\subsection{Willingness to Pay Estimates for Water Quality through the Adoption of EFF Practices}

Most of the respondents, $88.1 \%$, interestingly, are willing to pay a tax to improve the water quality along Soyang Lake (Table S2). This might be attributed to several discussions in the mass media with environmental policy makers and scientists of South Korea about maintaining potable water quality during the summer season. It means that the clean water availability from the river basin has been deemed important to respondents in downstream areas. In the bivariate probit model, the result shows that the presented bid values have a negative and statistically significant effect on the respondents' probability of accepting the bid. This indicates that the higher the bid values respondents have, the lower the willingness to pay is in the study area. In addition, Buyers is considered as a hypothesis-specific variable, assuming that it would appear to have an influence on the WTP for the water quality improvement through conversion to EFF, since the respondents who have bought EFF products can have more environmental and health concerns. The result shows that the variable Buyers has a positive and statistically significant effect on the household's probability of accepting the bid. This means that the consumers of EFF products would have more interests in the WTP, while its coefficient appears to have minimal effects on the WTP.

Based on the bivariate probit model, the expected mean and median WTPs were calculated in 95\% confidence interval for the WTP measures of Krinsky and Robb. The expected mean WTP for water improvement by converting to EFF is KRW 36,115 per household per year. The estimated mean WTP accounts for about $0.08 \%$ of the average annual income per household of Seoul citizens reported by Statistic Korea in 2013 [44]. To the best of our knowledge, none of the previous studies in South Korea revealed WTP estimation for water quality improvement through the conversion to EFF, as a way to reduce the negative externality from intensively managed farmlands causing water turbidity problem. Our findings are consistent with the current literature on the WTP for improving water quality in South Korea [19] and in line with Choi et al. [20], who report that the mean annual WTP for a land use restriction policy in the upstream areas was KRW 34,320 per household.

\subsection{Key Factors Influencing the Willingness to Pay for Water Quality Improvement Combined with EFF Practices}

In an OLS model, our findings indicate that the predicted probability of the WTP for the water quality increases as future purchase intention for EFF products increases. This is in line with previous 
studies, showing that EFF products' consumption is connected with consumers' attitude towards environment and their behavior toward environmental conservation $[45,46]$. In addition, our result implies that the higher awareness for labels of EFF products increases the probability of accepting the WTP for water quality improvement through the adoption of EFF. These results are in line with existing findings, implying that the awareness of labels for EFF products would have a positive impact on the WTP for the price premium towards organic products [47-49]. Regarding the marginal effects for the statistically significant variables, the calculated values in Future purchase intension of current consumers with EFF products and Label are on average KRW 3120 and KRW 924 per year for households respectively. These results are consistent with previous researches which emphasized Seoul citizens' preferences for environment improvement and food security and the expected WTP for the water quality conservation in South Korea [19,50].

\subsection{Upstream Farmers' Response for Their Farming Practices and Income Loss of EFF Farmers during Transition Period}

In upstream farm household survey targeting conventional and partially converted farmers, we found that about a half of the farmers are not willing to convert to EFF. One of the main reasons not to adopt the EFF came from the low profitability of EFF. This is consistent with several studies that show that this is a crucial determinant for adopting conservation practices in watersheds [26-30] and barrier for adopting organic farming in agricultural land use management [31-33]. Moreover, the result is also in line with the previous studies [51-55], which report that economic and institutional barriers such as unstable production and lack of financial support from governments for the adoption of organic farming.

Finally, the aggregate monetary WTPs by the number of total downstream citizens are KRW 151 billion with a range from KRW 114 billion to KRW 246 billion. The total benefits from the water quality improvement resulting from changes in EFF practices can be compared with the costs that upstream farmers can incur through the conversion. Thus, our result implies that the aggregate WTPs might be enough to cover the required costs in the conversion, as the average income loss accounts for about $40 \%$ of the aggregate WTPs.

\section{Conclusions}

Our study estimated the average annual WTP for water quality improvement of the Soyang Lake targeting to the downstream households. The expected WTP for the water quality through the adoption of EFF was calculated to be about KRW 36,115 per household per year. The total aggregate WTPs in the downstream areas were enough to cover the costs required through the conversion to EFF in the upstream area. The estimated values imply downstream citizens can assign the benefit from the water-related services to the investment for water quality conservation related to agriculture. This paper provides valuable information for sustainable water resource management as provided an importance for water quality protection combined with agricultural practices.

It should be noted that there are still several limitations of our study. The calculated income loss in the farmer survey is not likely to be equal to the exact reduced costs of the each farm households during their transition period. In addition, we did not consider several other factors affecting the price fluctuation such as which crops cultivated and seasonal effects. With a small sample size of farmers, our study investigated only a fixed profit in the survey year. We suggest further investigations for farmers' willingness to accept for water quality that consider various socio-economic characteristics in valuation statements. Further research should be needed to extend the sample and to improve the estimation of the willingness to accept for water quality improvement.

Regarding the downstream household survey, the targeted downstream households at the market might have potentially biased outcomes due to the difference in socio-economic characteristics of each group. Thus, future studies should be done by extending the scope at multiple stakeholders to 
investigate the various characteristics. Moreover, methodologically, attempts to use other payment vehicles should be made to explore heterogeneous consumers' preferences using CVM.

In the PES scheme, future research needs to compare local impacts of abolishing direct payments and on the analysis based on different policy instruments. Moreover, evaluation of the economic benefits and costs by emphasizing dual role relationships between upstream farmers and downstream consumers is recommended. In terms of their effectiveness and efficiency to facilitate the conversion to EFF for sustainable water services, an integrated management policy should be strengthened. Our analysis obtained by an empirical case study could be extended with spatial modeling studies such as invest, GIS, agent based modeling in integrated water resource management.

With respect to environmental problems with excessively abundant nutrients, many previous studies focused on water pollution treatment for water quality improvement and treatment plants for efficient diffuse sources management [56-59]. Some research has considered the relationships between abatement measures and an impact on nutrient loads in water basin [60-62]. As our paper focused on the WTP analysis for water pollution abatement through the adoption of EFF using CVM, further studies associated with water pollution treatment are essential for water quality improvements.

Furthermore, in our study, there is still insufficient information that concerns trading costs in the river basin. A recent review of the literatures shows a focus on the emerging water quality trading markets which are crucial for water quality improvement $[63,64]$. Several literatures have taken into account cost-effective solutions for combating eutrophication of coastal ecosystem in spatial and dynamic management [65-67]. In order to determine a more proper policy programs for the cost-effective conservation practices, several studies suggest the applications of transaction costs, trading costs and imposed trading ratios in emerging water quality trading markets. Thus, further studies for cost-effective conservation practices need to be developed in our study area as well.

Supplementary Materials: The following are available online at www.mdpi.com/2073-4441/9/7/511/s1, Table S1: Profile of downstream survey respondents; Table S2: Summary for the yes response regarding the WTP of downstream respondents; Table S3: Response results for bid values and proportion of downstream respondents; Table S4: Description of the variables used in the bivariate Probit model; Table S5: Reasons for the no response regarding WTP of downstream respondents; Table S6: Descriptions of variables used in OLS model and their marginal effects; Table S7: Average income loss during transition periods from conventional farming to environmentally friendly farming; Table S8: The reasons not to adopt environmentally friendly farming of upstream farmers; Table S9: The comparison of mean values between survey sample and Seoul samples.

Acknowledgments: This study was carried out as part of the International Research Training Group TERRECO (GRK 1565/1) funded by the Deutsche Forschungsgemeinschaft (DFG) at the University of Bayreuth, Germany and Kangwon National University, Chuncheon, South Korea. This publication was funded by the German Research Foundation (DFG) and the University of Bayreuth in the funding programme Open Access Publishing.

Author Contributions: All authors developed the research design and contributed to the writing of the paper. Saem Lee collected the data and did the data analysis, wrote the manuscript. Trung Thanh Nguyen and Hyun No Kim performed econometric analysis and edited the manuscript. Hio-Jung Shin and Thomas Koellner contributed to reviewing and editing the manuscript.

Conflicts of Interest: The authors declare no conflict of interest.

\section{References}

1. Lee, S.; Nguyen, T.T.; Poppenborg, P.; Shin, H.J.; Koellner, T. Conventional, Partially Converted and Environmentally Friendly Farming in South Korea: Profitability and Factors Affecting Farmers' Choice. Sustainability 2016, 8, 704. [CrossRef]

2. Nguyen, T.T.; Ruidisch, M.; Koellner, T.; Tenhunen, J. Synergies and tradeoffs between nitrate leaching and net farm income: The case of nitrogen best management practices in South Korea. Agric. Ecosyst. Environ. 2014, 186, 160-169. [CrossRef]

3. Hanemann, W.M. Valuing the environment through contingent valuation. J. Econ. Perspect. 1994, 8, $19-43$. [CrossRef] 
4. Bateman, I.J.; Carson, R.T.; Day, B.; Hanemann, M.; Hanleys, N.; Hett, T.; Jones-Lee, M.; Loomes, G.; Mourato, S.; Özdemiroglu, E.; et al. Economic Valuation with Stated Preference Techniques: A Manual; Edward Elgar: Cheltenham, UK, 2002; ISBN 1840649194.

5. Shah, S.A.; Hoag, D.L.K.; Davies, S. Household preferences and willingness to pay (WTP) for freshwater quality improvement in Pakistan's Swat River Valley. Environ. Dev. Sustain. 2016, 18, 1081-1093. [CrossRef]

6. Aref, F. Farmers' Participation in Agricultural Development: The Case of Fars Province, Iran. Indian J. Sci. Technol. 2011, 4, 155-158.

7. Zheng, S.; Wang, Z.; Awokuse, T.O. Determinants of Producers' Participation in Agricultural Cooperatives: Evidence from Northern China. Appl. Econ. Perspect. Policy 2012, 34, 167-186. [CrossRef]

8. Chandrasekaran, K.; Devarajulu, S.; Kuppannan, P. Farmers' Willingness to Pay for Irrigation Water: A Case of Tank Irrigation Systems in South India. Water 2009, 1, 5-18. [CrossRef]

9. Afroz, R.; Hanaki, K.; Hasegawa-Kurisu, K. Willingness to pay for waste management improvement in Dhaka city, Bangladesh. J. Environ. Manag. 2009, 90, 492-503. [CrossRef] [PubMed]

10. Basha, M.B.; Mason, C.; Shamsudin, M.F.; Hussain, H.I.; Salem, M.A. Consumers Attitude towards Organic Food. Procedia Econ. Financ. 2015, 31, 444-452. [CrossRef]

11. Khai, H.V. Assessing Consumer Preferences for Organic Vegetables: A Case Study in the Mekong Delta, Vietnam. Inf. Manag. Bus. Rev. 2015, 7, 41-47.

12. Sivathanu, B. Factors Affecting Consumer Preference towards the Organic Food Purchases. Indian J. Sci. Technol. 2015, 8, 1-6. [CrossRef]

13. Hsu, S.-Y.; Chang, C.-C.; Lin, T.T. An analysis of purchase intentions toward organic food on health consciousness and food safety with/under structural equation modeling. Br. Food J. 2016, 118, 200-216. [CrossRef]

14. Rigby, D.; Cáceres, D. Organic farming and the sustainability of agricultural systems. Agric. Syst. 2001, 68, 21-40. [CrossRef]

15. Hass, R.; Canavari, M.; Slee, B.; Tong, C.; Anurugsa, B. Looking East, Looking West: Organic and Quality Food Marketing in Asia and Europe; Academic Publishers: Wageningen, The Netherlands, 2010.

16. Barataud, F.; Aubry, C.; Wezel, A.; Mundler, P. Management of drinking water catchment areas in cooperation with agriculture and the specific role of organic farming. Experiences from Germany and France. Land Use Policy 2014, 36, 585-594. [CrossRef]

17. Schoumans, O.F.; Chardon, W.J.; Bechmann, M.E.; Gascuel-Odoux, C.; Hofman, G.; Kronvang, B.; Rubæk, G.H.; Ulén, B.; Dorioz, J.-M. Mitigation options to reduce phosphorus losses from the agricultural sector and improve surface water quality: A review. Sci. Total Environ. 2014, 468-469, 1255-1266. [CrossRef] [PubMed]

18. Sun, W.-X.; Huang, B.; Qu, M.-K.; Tian, K.; Yao, L.-P.; Fu, M.-M.; Yin, L.-P. Effect of Farming Practices on the Variability of Phosphorus Status in Intensively Managed Soils. Pedosphere 2015, 25, 438-449. [CrossRef]

19. Shin, H.-J.; Jeon, C.-H.; Choi, I.-C.; Yeon, I.-C. Estimation of Beneficiary's Willingness to Pay in Mid.Down-Stream Area to the Water Quality Improvements in Upper Bukhan River Basin. Seoul Stud. 2009, 10, 91-106. (In Korean)

20. Choi, I.-C.; Kim, H.-N.; Shin, H.-J.; Tenhunen, J.; Nguyen, T.T. Willingness to Pay for a Highland Agricultural Restriction Policy to Improve Water Quality in South Korea: Correcting Anomalous Preference in Contingent Valuation Method. Water 2016, 8, 547. [CrossRef]

21. Fripp, E.; Shantiko, B. Payment for Ecosystem Services (PES): Assessment of PES Potential in Kapuas Hulu; Working Paper 165; Center for International Forestry Research (CIFOR): Bogor, Indonesia, 2014.

22. Organisation for Economic Co-operation and Development (OECD). The Environmental Effects of Agricultural Land Diversion Programs; OECD: Paris, France, 1997.

23. Baylis, K.; Peplow, S.; Rausser, G.; Simon, L. Agri-environmental policies in the EU and United States: A comparison. Ecol. Econ. 2008, 65, 753-764. [CrossRef]

24. Gómez-Baggethun, E.; de Groot, R.; Lomas, P.L.; Montes, C. The history of ecosystem services in economic theory and practice: From early notions to markets and payment schemes. Ecol. Econ. 2010, 69, 1209-1218. [CrossRef]

25. Boisvert, V.; Méral, P.; Froger, G. Market-Based Instruments for Ecosystem Services: Institutional Innovation or Renovation? Soc. Nat. Resour. 2013, 26, 1122-1136. [CrossRef] 
26. Lamba, P.; Filson, G.; Adekunle, B. Factors affecting the adoption of best management practices in southern Ontario. Environmentalist 2009, 29, 64. [CrossRef]

27. Ullah, A.; Shah, S.N.M.; Ali, A.; Naz, R.; Mahar, A.; Kalhoro, S.A. Factors affecting the adoption of organic farming in Peshawar-Pakistan. Agric. Sci. 2015, 6, 587-593. [CrossRef]

28. Patil, S.; Reidsma, P.; Shah, P.; Purushothaman, S.; Wolf, J. Comparing conventional and organic agriculture in Karnataka, India: Where and when can organic farming be sustainable? Land Use Policy 2014, 37, 40-51. [CrossRef]

29. Sarker, M.A.; Itohara, Y.; Hoque, M. Determinants of adoption decisions: The case of organic farming in Bangladesh. Ext. Farming Syst. J. 2010, 5, 39-46.

30. Mabuza, M.L.; Sithole, M.M.; Wale, E.; Ortmann, G.F.; Darroch, M.A.G. Factors influencing the use of alternative land cultivation technologies in Swaziland: Implications for smallholder farming on customary Swazi Nation Land. Land Use Policy 2013, 33, 71-80. [CrossRef]

31. Constance, D.-H.; Choi, J.-Y. Overcoming the Barriers to Organic Adoption in the United States: A Look at Pragmatic Conventional Producers in Texas. Sustainability 2010, 2, 163-188. [CrossRef]

32. Mahoney, P.R.; Olson, K.D.; Porter, P.M.; Huggins, D.R.; Perillo, C.A.; Kent Crookston, R. Profitability of organic cropping systems In Southwestern Minnesota. Renew. Agric. Food Syst. 2004, 19, 35-46. [CrossRef]

33. Delbridge, T.-A.; King, R.P. Transitioning to Organic Crop Production: A Dynamic Programming Approach. J. Agric. Resour. Econ. 2016, 41, 481-498.

34. Nyongesa, J.M.; Bett, H.K.; Lagat, J.K.; Ayuya, O.I. Estimating farmers' stated willingness to accept pay for ecosystem services: Case of Lake Naivasha watershed Payment for Ecosystem Services scheme-Kenya. Ecol. Process. 2016, 5, 15. [CrossRef]

35. Cummings, R.G.; Brookshire, D.S.; Schulze, W.D. Valuing Environmental Goods: A State of the Arts Assessment of the Contingent Valuation Method; Roweman and Allanhelds: Totowa, NJ, USA, 1986.

36. Mitchell, R.C.; Carson, R.T. Using Surveys to Value Public Goods: The Contingent Valuation Method; Resource for the Future: Washington, DC, USA, 1989.

37. Freeman, A.M. The Benefits of Environmental Improvement: Theory and Practice; Johns Hopkins University Press: Baltimore, MD, USA, 1979.

38. Arrow, K.J.; Solow, R.M.; Portney, P.R.; Leamer, E.E.; Radner, R.; Schuman, H. Report of the NOAA-Panel on Contingent Valuation. Fed. Regist. 1993, 58, 4601-4614.

39. Hanemann, W.M.; Loomis, J.; Kanninen, B. Statistical efficiency of double bounded dichotomous choice contingent valuation. Am. J. Agric. Econ. 1991, 73, 1255-1263. [CrossRef]

40. Haab, T.C.; McConnell, K.E. Valuing Environmental and Natural Resources: The Econometrics of Non-Market Valuation; Edward Elgar Publishing: Cheltenham, UK, 2002.

41. Hanemann, W.M. Welfare Evaluations in Contingent Valuation Experiments with Discrete Responses. Am. J. Agric. Econ. 1984, 66, 332-341. [CrossRef]

42. Cameron, T.A. Interval Estimates of Non-Market Resource Values from Referendum Contingent valuation Surveys. Land Econ. 1991, 67, 413-421. [CrossRef]

43. Kennedy, P.E. Estimation with Correctly Interpreted Dummy Variables in Semilogarithmic Equations. Am. Econ. Rev. 1981, 71, 801.

44. Seoul, Seoul Statistical Yearbook, Seoul Metropolitan Government. 2014. Available online: http://ebook. seoul.go.kr/Viewer/ZV975O62TBCW (accessed on 31 January 2017).

45. Hughner, R.S.; Mcdonagh, P.; Prothero, A.; Shultz, C.J.; Stanton, J. Who are organic food consumers? A compilation and review of why people purchase organic food. J. Consum. Behav. 2007, 6, 1479-1838. [CrossRef]

46. Owusu, V.; Anifori, M.O. Consumer Willingness to Pay a Premium for Organic Fruit and Vegetable in Ghana. Int. Food Agribus. Manag. 2013, 16, 67-86.

47. Aryal, K.P.; Chaudhary, P.; Pandit, S.; Sharma, G. Consumers' Willingness to Pay for Organic Products: A Case from Kathmandu Valley. J. Agric. Environ. 2009, 10, 15-26. [CrossRef]

48. Haghiri, M.; Hobbs, J.E.; McNamara, M.L. Assessing consumer preferences for organically grown fresh fruit and vegetables in Eastern New Brunswick. Int. Food Agribus. Manag. 2009, 12, 81-99.

49. Janssen, M.; Hamm, U. The mandatory EU logo for organic food: Consumer perceptions. J. Consum. Behav. 2012, 114, 335-352. [CrossRef] 
50. Kim, H.; Heo, S.W.; Lee, J.Y. An Analysis of Social and Economic Effects on the Certification for Environment-Friendly Agricultural Products Dankook University Report; National Agricultural Products Quality Management Service (NAQS): Seoul, Korea, 2009. (In Korean)

51. Stevenson, J.R.; Serraj, R.; Cassman, K.G. Evaluating conservation agriculture for small-scale farmers in Sub-Saharan Africa and South Asia. Agric. Ecosyst. Environ. 2014, 187, 1-10. [CrossRef]

52. Tiwari, K.R.; Sitaula, B.K.; Nyborg, I.L.; Paudel, G.S. Determinants of Farmers' Adoption of Improved Soil Conservation Technology in a Middle Mountain Watershed of Central Nepal. Environ. Manag. 2008, 42, 210-222. [CrossRef] [PubMed]

53. Menozzi, D.; Martina, F.; Michele, D. Farmer's motivation to adopt sustainable agricultural practices. $B A E$ 2015, 4, 125-147. [CrossRef]

54. Nguyen, T.T.; Hoang, V.-N.; Seo, B. Cost and environmental efficiency of rice farms in South Korea. Agric. Econ. 2012, 43, 369-378. [CrossRef]

55. Ryan, R.; Erickson, D.; De Young, R. Farmers' Motivations for Adopting Conservation Practices along Riparian Zones in a Mid-western Agricultural Watershed. J. Environ. Plan. Manag. 2003, 46, 19-37. [CrossRef]

56. Roebeling, P.C.; Cunha, M.C.; Arroja, L.; van Grieken, M.E. Abatement vs. treatment for efficient diffuse source water pollution management in terrestrial-marine systems. Water Sci. Technol. 2015, 72, 730-737. [CrossRef] [PubMed]

57. Gren, I.-M. Resilience value of constructed coastal wetlands for combating eutrophication. Ocean Coast Manag. 2010, 53, 358-365. [CrossRef]

58. Laukkanen, M.; Huhtala, A. Optimal Management of a Eutrophied Coastal Ecosystem: Balancing Agricultural and Municipal Abatement Measures. Environ. Resour. Econ. 2008, 39, 139-159. [CrossRef]

59. Roebeling, P.C.; Van Grieken, M.E.; Webster, A.J.; Biggs, J.; Thorburn, P. Cost-effective water quality improvement in linked terrestrial and marine ecosystems: A spatial environmental-economic modelling approach. Mar. Freshw. Res. 2009, 60, 1150-1158. [CrossRef]

60. Gren, I.M. Adaptation and mitigation strategies for controlling stochastic water pollution: An application to the Baltic Sea. Ecol. Econ. 2008, 66, 337-347. [CrossRef]

61. Söderqvist, T. Constructed wetlands as nitrogen sinks in southern Sweden: An empirical analysis of cost determinants. Ecol. Eng. 2002, 19, 161-173. [CrossRef]

62. Motallebi, M.; Hoag, D.L.; Tasdighi, A.; Arabi, M.; Osmond, D.L. An economic inquisition of water quality trading programs, with a case study of Jordan Lake, NC. J. Environ. Manag. 2017, 193, 483-490. [CrossRef] [PubMed]

63. Corrales, J.; Naja, G.M.; Bhat, M.G.; Miralles-Wilhelm, F. Water quality trading opportunities in two sub-watersheds in the northern Lake Okeechobee watershed. J. Environ. Manag. 2017, 196, 544-559. [CrossRef] [PubMed]

64. Elofsson, K. Cost-effective reductions of stochastic agricultural loads to the Baltic Sea. Ecol. Econ. 2003, 47, 13-31. [CrossRef]

65. Gren, I.M.; Savchuk, O.P.; Jansson, T. Cost-Effective Spatial and Dynamic Management of a Eutrophied Baltic Sea. Mar. Resour. Econ. 2013, 28, 263-284. [CrossRef]

66. Lescot, J.M.; Bordenave, P.; Petit, K.; Leccia, O.A. spatially distributed cost-effectiveness analysis framework for controlling water pollution. Environ. Model. Softw. 2013, 41, 107-122. [CrossRef]

67. Laukkanen, M.; Ekholm, P.; Huhtala, A.; Pitkänen, H.; Kiirikki, M.; Rantanen, P.; Inkala, A. Integrating ecological and economic modeling of eutrophication: Toward optimal solutions for a coastal area suffering from sediment release of phosphorus. Ambio 2009, 38, 225-235. [CrossRef] [PubMed]

(C) 2017 by the authors. Licensee MDPI, Basel, Switzerland. This article is an open access article distributed under the terms and conditions of the Creative Commons Attribution (CC BY) license (http://creativecommons.org/licenses/by/4.0/). 